Case Report

\title{
Acute Kidney Injury Associated with Linagliptin
}

\author{
Deepak K. Nandikanti, ${ }^{1}$ Elvira O. Gosmanova, ${ }^{2}$ and Aidar R. Gosmanov ${ }^{3}$ \\ ${ }^{1}$ Kidney Specialists of Southern Nevada, Las Vegas, NV 89106, USA \\ ${ }^{2}$ Nephrology Section, Stratton VA Medical Center, Albany, NY 12208, USA \\ ${ }^{3}$ Endocrinology Section, Stratton VA Medical Center, Albany, NY 12208, USA
}

Correspondence should be addressed to Deepak K. Nandikanti; doc.deeps@gmail.com

Received 11 July 2015; Accepted 21 January 2016

Academic Editor: John Broom

Copyright (C) 2016 Deepak K. Nandikanti et al. This is an open access article distributed under the Creative Commons Attribution License, which permits unrestricted use, distribution, and reproduction in any medium, provided the original work is properly cited.

Linagliptin is a dipeptidyl peptidase-IV (DPP-IV) inhibitor that is approved for the treatment of type 2 diabetes mellitus. About $5 \%$ of linagliptin is eliminated by the kidneys and no dose adjustment is recommended in kidney impairment. We report a first case of linagliptin-associated acute kidney injury (AKI) in a patient with preexisting chronic kidney disease (CKD). We hypothesize that AKI was due to renal hypoperfusion from linagliptin-induced natriuresis and intravascular volume contraction in the setting of concomitant lisinopril use, which is known to impair autoregulation and potentiate hypotension-induced AKI. It may be prudent to exert caution and closely monitor kidney function when initiating linagliptin in combination with ACE-inhibitors in CKD patients.

\section{Introduction}

Linagliptin is a dipeptidyl peptidase-4 (DPP-4) inhibitor that was approved for the treatment of type 2 diabetes in 2011. A single daily dose of linagliptin is well tolerated [1]. In contrast with other DPP-4 inhibitors, kidney excretion has minimal contribution for linagliptin elimination $(\sim 5 \%)$ and no dose adjustment is recommended in patients with kidney impairment [2]. Linagliptin has been used in patients with chronic kidney disease (CKD) [3]; however, the safety of linagliptin in combination with renin-angiotensin system (RAS) blockers in CKD patients is unknown. Here, we report a case of linagliptin-associated acute kidney injury (AKI) in a patient with preexisting CKD.

\section{Case Description}

A 54-year-old African-American male with hypertension treated with multiple medications, including lisinopril $80 \mathrm{mg}$ daily, amlodipine $10 \mathrm{mg}$ daily, hydralazine $50 \mathrm{mg}$ trice daily, and clonidine $0.2 \mathrm{mg}$ twice daily; type 2 diabetes controlled with glimepiride $1 \mathrm{mg}$ daily; and stage $4 \mathrm{CKD}$ due to diabetic kidney disease was evaluated in nephrology office during routine follow-up visit. Blood pressure was $156 / 70 \mathrm{mmHg}$, which was similar to home measurements. The remaining physical examination was unremarkable. Kidney function was stable with serum creatinine (SCr) of $4.3 \mathrm{mg} / \mathrm{dL}$ (estimated glomerular filtration rate (eGFR) of $18 \mathrm{~mL} / \mathrm{min} / 1.73 \mathrm{~m}^{2}$ ) and blood urea nitrogen of $64 \mathrm{mg} / \mathrm{dL}$. Potassium level was elevated at $6.4 \mathrm{mmol} / \mathrm{L}$. Hyperkalemia was attributed to several glasses of orange juice that patient was ingesting daily in the last week for the prevention and treatment of recurrent episodes of hypoglycemia. Blood glucose was $70 \mathrm{mg} / \mathrm{dL}$ and hemoglobin Alc was 5.5\%; therefore, glimepiride was discontinued and linagliptin $5 \mathrm{mg}$ once daily was initiated to reduce the incidence of hypoglycemia. Due to elevated potassium, electrolyte measurement was reassessed one week following linagliptin initiation. At that time, SCr and BUN increased to $7.0 \mathrm{mg} / \mathrm{dL}$ and $101 \mathrm{mg} / \mathrm{dL}$, respectively, and hyperkalemia persisted. The patient was admitted to the hospital for evaluation of AKI. On admission, he denied recurrent hypoglycemia, vomiting or diarrhea, or any new medications with the exception of linagliptin. The patient lived with his mother who administered his medications. She denied any changes in compliance and conformed that the patient was in his usual health when he was contacted about elevated SCr. During physical examination blood pressure was $120 / 57 \mathrm{mmHg}$ with no orthostatic changes. The patient's weight was $2.5 \mathrm{~kg}$ lower 


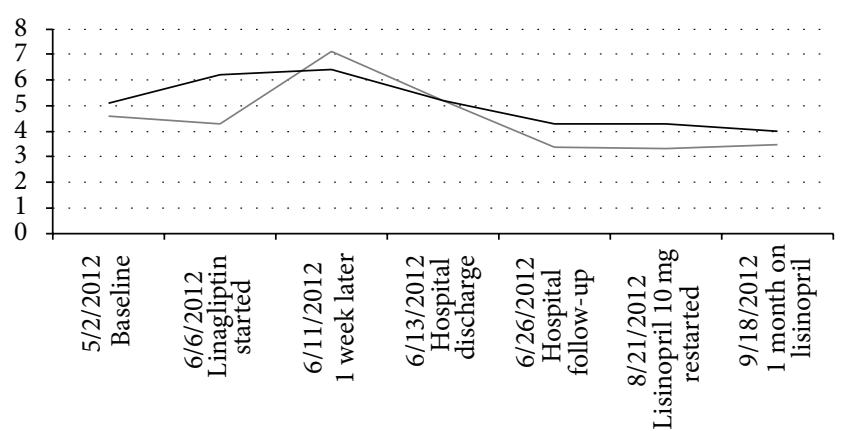

- Serum creatinine $(\mathrm{mg} / \mathrm{dL})$

_ Serum potassium $(\mathrm{mmol} / \mathrm{L})$

FIGURE 1: Time-course of changes in serum creatinine and serum potassium in relationship with linagliptin use.

as compared with his weight in nephrology clinic 1 week ago. Skin turgor was slightly reduced and no signs of peripheral edema were observed. Urinalysis was bland. Fractional excretion of sodium was $3.4 \%$. Linagliptin was discontinued, as the onset of AKI on CKD coincided with linagliptin initiation. Because patient's weight and blood pressure were significantly lower than the usual for him with no signs of infection, the presence of volume depletion was suspected and lisinopril was discontinued. After administration of $2 \mathrm{~L}$ of normal saline over 24 hours and oral kayexalate, $\mathrm{SCr}$ and potassium levels improved to $5.7 \mathrm{mg} / \mathrm{dL}$ and $5.1 \mathrm{mmol} / \mathrm{L}$, respectively. Blood pressure increased to $142 / 76 \mathrm{mmHg}$. The patient refused any further interventions and was discharged home. While continuing to hold lisinopril and linagliptin, $\mathrm{SCr}$ improved to $3.4 \mathrm{mg} / \mathrm{dL}$ in 10 days and remained stable for the next 2 months. Due to chronic proteinuria, a low dose of lisinopril at $10 \mathrm{mg}$ daily was restarted. SCr was unchanged at $3.5 \mathrm{mg} / \mathrm{dL} 4$ weeks following lisinopril initiation (Figure 1). Patient did not require any hypoglycemic medications and was following a diabetic diet.

\section{Discussion}

This report describes patient characteristics and course of AKI after the initiation of linagliptin. The efficacy and safety of linagliptin has been investigated in the recent 52-week study involving diabetic patients with estimated glomerular filtration rate (eGFR) of less than $30 \mathrm{~mL} / \mathrm{min} / 1.73 \mathrm{~m}^{2}$ [3]. Overall, the incidence of AKI in linagliptin-treated patients was $7.4 \%$ and it was similar to the control group. The investigators believed that AKI events were not related to linagliptin; however, no additional details regarding AKI cases were provided. Moreover, it is unknown if linagliptin-treated patients were concomitantly receiving RAS-blockers. In rats, the DDP-4 inhibition downregulates $\mathrm{Na}^{+} / \mathrm{H}^{+}$exchanger in the proximal renal tubule, which, in turn, leads to natriuresis, diuresis, and attenuation of blood pressure $[4,5]$. In the present case, we also observed mild reduction in blood pressure at the time of AKI. While the normal kidney response during hypotension is to preserve sodium, we found an increased fractional urinary excretion of sodium and weight reduction that may be consistent with diuretic effect of linagliptin. In the present case, we hypothesize that AKI occurred from renal hypoperfusion caused by linagliptin-induced natriuresis and intravascular volume contraction in the setting of concomitant lisinopril administration. ACE-inhibitors are known to impair autoregulation and potentiate hypotension-induced AKI [6]. It may be prudent to exert caution when linagliptin is initiated in combination with ACEinhibitors in patients with limited kidney reserve. Of note, a case of transient AKI associated with linagliptin use was reported in a patient with normal renal function who was also on ACE-inhibitor [7]. Therefore, we recommend to closely monitoring kidney function and blood pressure after linagliptin initiation in diabetic patients with advanced CKD also treated with ACE-inhibitors.

\section{Conflict of Interests}

The authors declare that there is no conflict of interests regarding the publication of this paper.

\section{References}

[1] D. R. Owens, R. Swallow, K. A. Dugi, and H. J. Woerle, "Efficacy and safety of linagliptin in persons with Type2 diabetes inadequately controlled by a combination of metformin and sulphonylurea: a 24-week randomized study," Diabetic Medicine, vol. 28, no. 11, pp. 1352-1361, 2011.

[2] Tradjenta (Linaglitpin). Prescribing Information, Boehringer Ingelheim Pharmaceuticals, 2012.

[3] J. B. McGill, L. Sloan, J. Newman et al., "Long-term efficacy and safety of linagliptin in patients with type 2 diabetes and severe renal impairment: a 1-year, randomized, double-blind, placebocontrolled study," Diabetes Care, vol. 36, no. 2, pp. 237-244, 2013.

[4] A. C. C. Girardi, L. E. Fukuda, L. V. Rossoni, G. Malnic, and N. A. Rebouças, "Dipeptidyl peptidase IV inhibition downregulates $\mathrm{Na}^{+}-\mathrm{H}^{+}$exchanger NHE3 in rat renal proximal tubule," American Journal of Physiology-Renal Physiology, vol. 294, no. 2, pp. F414-F422, 2008.

[5] B. P. Pacheco, R. O. Crajoinas, G. K. Couto et al., "Dipeptidyl peptidase IV inhibition attenuates blood pressure rising in young spontaneously hypertensive rats," Journal of Hypertension, vol. 29, no. 3, pp. 520-528, 2011.

[6] A. C. Schoolwerth, D. A. Sica, B. J. Ballermann, and C. S. Wilcox, "Renal considerations in angiotensin converting enzyme inhibitor therapy: a statement for healthcare professionals from the Council on the Kidney in Cardiovascular Disease and the Council for High Blood Pressure Research of the American Heart Association," Circulation, vol. 104, no. 16, pp. 1985-1991, 2001.

[7] K. Kutoh, "Potential linagliptin-induced renal impairment," Journal of Medical Cases, vol. 3, pp. 361-364, 2012. 


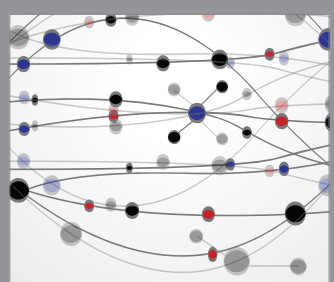

The Scientific World Journal
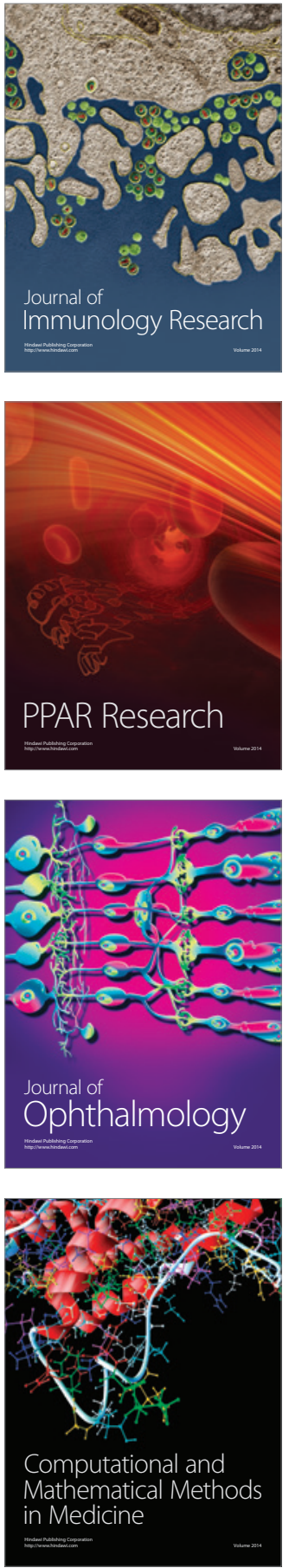

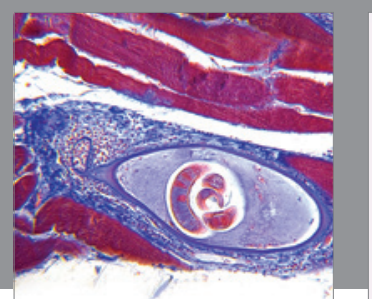

Gastroenterology Research and Practice

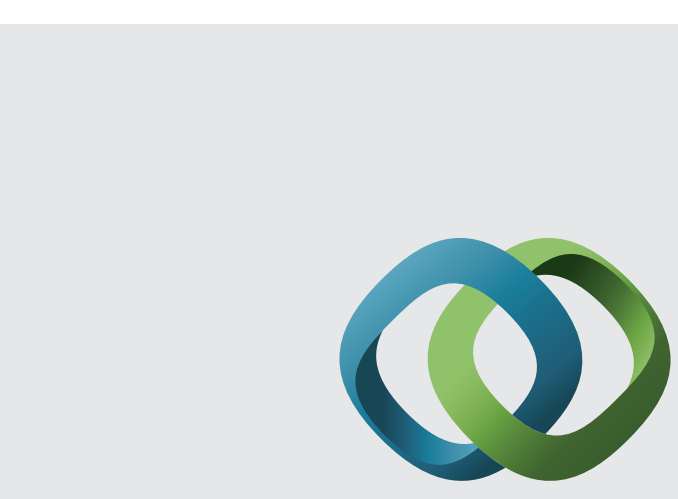

\section{Hindawi}

Submit your manuscripts at

http://www.hindawi.com
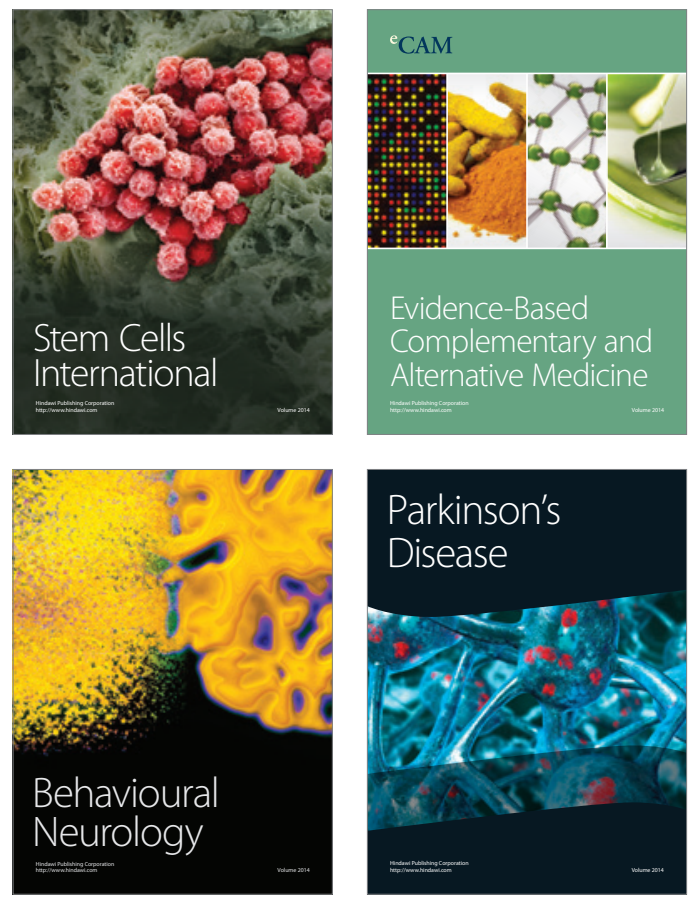
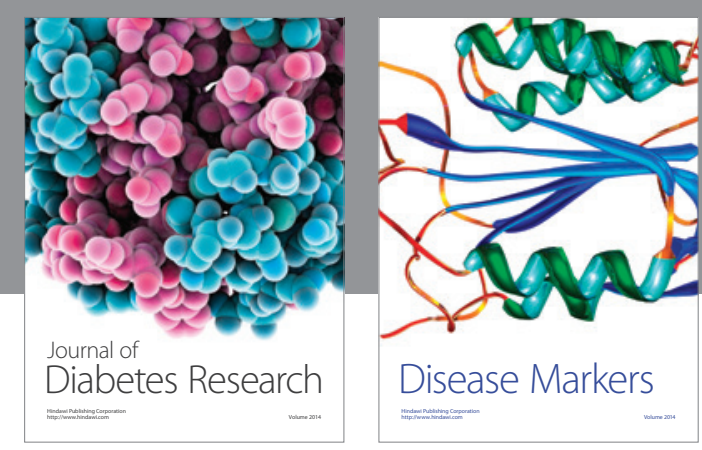

Disease Markers
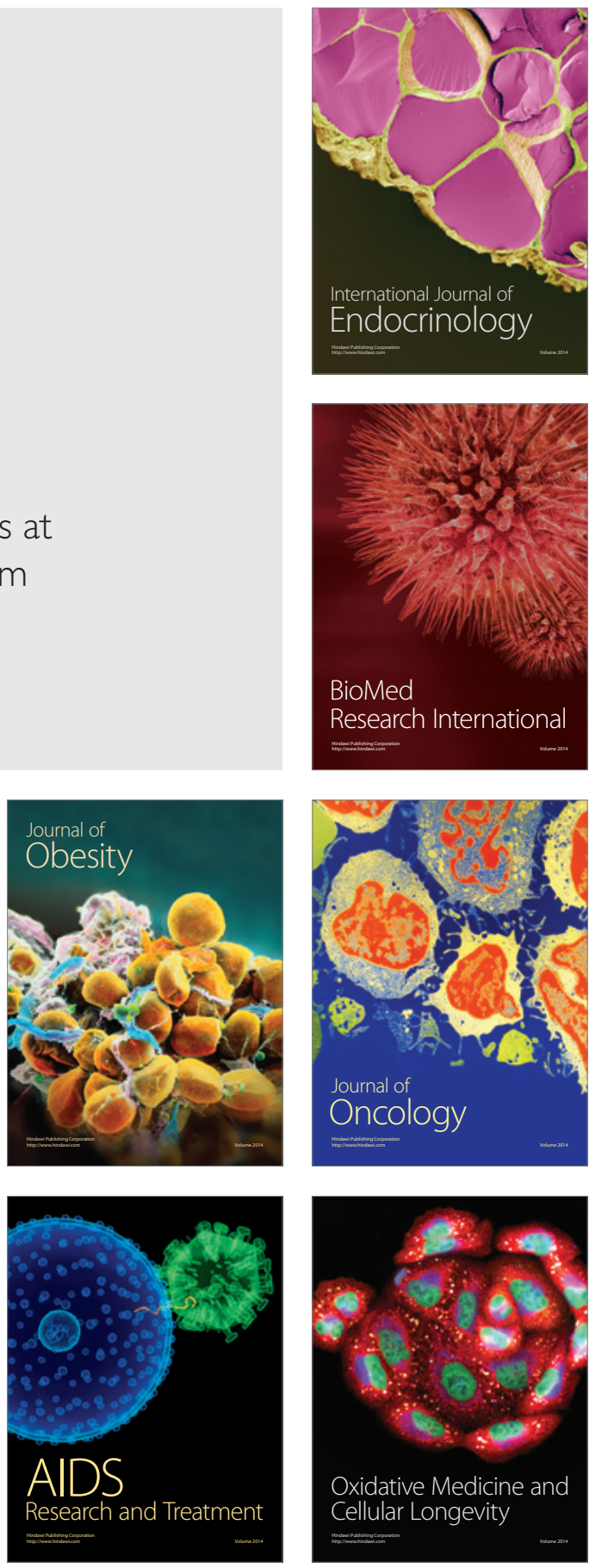